Mundo Revista de agrario
Mundo Agrario, abril 2018, vol. 19, n 40, e082. ISSN 1515-5994

Universidad Nacional de La Plata

Facultad de Humanidades y Ciencias de la Educación

Centro de Historia Argentina y Americana

\title{
Rosa Congost, Jorge Gelman, Rui Santos (Edits.) Property Rights in Land: Issues in Social, Economic and Global History. Número 48 de Perspectives ín economic and social history. London and New York: Routledge, 2017
}

\section{María Inés Carzolio}

Universidad Nacional de La Plata, Argentina

micarzolio@fibertel.com.ar

\section{Osvaldo Víctor Pereyra}

Universidad Nacional de La Plata, Argentina

vopereyra@gmail.com

\section{Guillermo Banzato}

Universidad Nacional de La Plata, Argentina gbanzato@gmail.com

Cita sugerida: Carzolio, M. I.; Pereyra, O. V. y Banzato, G. (2018). [Reseña del libro Property Rights in Land: Issues in Social, Economic and Global History de R. Congost, J. Gelman y R. Santos]. Mundo Agrario, 19 (40), e081. https://doi.org/10.24215/15155994e082

Recibido: 14 de febrero de 2018 - Aceptado: 1 de marzo de 2018 - Publicado: 26 de marzo de 2018

(c) (i) (2) Esta obra está bajo licencia Creative Commons Atribución-NoComercial-CompartirIgual 4.0 Internacional http://creativecommons.org/licenses/by-nc-sa/4.0/deed.es_AR 


\title{
Rosa Congost, Jorge Gelman, Rui Santos (Edits.) Property Rights in Land: Issues in Social, Economic and Global History. Número 48 de Perspectives in economic and social history. London and New York: Routledge, 2017
}

\author{
Maria Inés Carzolio \\ Universidad Nacional de La Plata, Argentina \\ micarzolio@fibertel.com.ar \\ Osvaldo Victor Pereyra \\ Universidad Nacional de La Plata, Argentina \\ vopereyra@gmail.com \\ Guillermo Banzato \\ Universidad Nacional de La Plata, Argentina \\ gbanzato@gmail.com
}

La compilación de artículos coordinada por tres prestigiosos historiadores -dos europeos y uno americano, recientemente fallecido- que cultivan la historia agraria y rural, tiene su inspiración en la XVI Conferencia de Historia Económica Mundial celebrada en Stellenbosch, Sudáfrica, en 2012, titulada "Las raíces del desarrollo económico".

La explicación más general atribuye las diferencias del desarrollo a las divergencias institucionales entre unas escasas sociedades europeas en las cuales las instituciones "buenas", económicamente eficientes, llegaron a formar las "raíces del desarrollo económico", y otras, mucho más numerosas -y menos afortunadas- en las cuales el proceso quedó atrapado por instituciones "malas", ineficientes, que no favorecían los incentivos del mercado para la inversión productiva y el comercio competitivo por el bloqueo ejercido por las élites establecidas, de modo que las innovaciones institucionales eran incapaces de conducirlas hacia un camino de desarrollo. La teoría de la dependencia con la de la transferencia de instituciones del Viejo al Nuevo Mundo durante la era de los imperios europeos, proporciona así una "genealogía" de las instituciones ineficientes, incluidos los derechos de propiedad mal distribuidos, mal definidos e inseguros, que obstaculizaron el desarrollo en algunos espacios postcoloniales.

Si bien la narrativa del desarrollo en la nueva historia económica institucional plantea el problema acerca de a quiénes se vieron socialmente beneficiados o perjudicados por los resultados de esas instituciones "buenas" o "malas", es preciso individualizar el "agente". Es decir, la forma en que los nuevos derechos de propiedad se apropiaron de alguna expropiación ejecutada sobre otros tuvo consecuencias distributivas y en la integración social. Pero si la narrativa neo-institucional pone el peso explicativo en las reglas, normas y creencias, así como en la agencia de las organizaciones estatales y de élite, esto se hace en detrimento del análisis histórico de las relaciones sociales concretas y de la agencia del proceso.

Los editores y los autores declaran "sentir que todo el debate sobre la eficiencia económica de las instituciones no tiene sentido”, y lo rechazan. Consideran:

las instituciones, como sistemas ejecutables de normas y reglas, solo pueden producir resultados a través de acciones concretas; por lo tanto, sus resultados, eficientes o no, dependen de quién, cómo y en qué medida las reglas y normas son apropiados como recursos, cómo se resisten a las restricciones y cómo ese equilibrio cambia con el tiempo.

Reivindican, como tarea de los historiadores y científicos sociales, "abrazar y comprender la pluralidad de las instituciones de propiedad y la dinámica de las relaciones sociales tejidas a su alrededor". 
Las preguntas amplias y exploratorias y una gama igualmente profusa de perspectivas, desde la historia local o regional hasta la global, desde la "historia desde abajo" a los enfoques "neo-institucionales" que buscan abordar un contexto social más amplio, tuvieron cabida en el volumen. En conjunto, los trabajos comprenden una variada gama de casos y temas, que permiten debatir sobre la naturaleza de los cambios en los derechos de propiedad, las relaciones sociales y de poder que ponen en juego esos derechos y sus asignaciones locales o específicas. En resumen, tratan acerca de la naturaleza históricamente contextualizada y contingente de tales derechos.

El volumen se inicia con el trabajo de José Vicente Serrao y Eugenia Rodríguez, que pone en guardia acerca de los logros concretos y diferencias que puede haber entre la voluntad de un gobierno para imponer nuevos derechos de propiedad sobre los grupos sociales - de una potencia colonialista sobre sociedades coloniales-y la forma en que estos últimos se apropian de los mismos. Se trata de observar, desde una perspectiva de historia global, la transferencia y adaptación de un modelo lusitano de derechos de propiedad enfitéutica a regiones colonizadas en el Estado de la India portugués -formado por regiones del subcontinente indio y la isla de Ceilán, además de las colonias del este de África en Mozambique- desde el siglo XVI hasta el siglo XIX. En tanto los dominios indios incluían territorios con tradiciones agrícolas y comerciales antiguas y regulaciones bien establecidas con respecto al uso y la apropiación de recursos, la región de Zambezi en Mozambique, poblada de sociedades seminómadas con agricultura de subsistencia, tenían menor control sobre la tierra. El caso presenta diversidad en cuanto al lapso y ausencia de homogeneidad social y política, dentro de la cual los autores describen la adaptación y evolución del modelo institucional, al que denominan "enfiteusis indoportuguesa", y sus resultados variables.

El ensayo de Mats Morell se centra en los cambios a largo plazo en los derechos de propiedad en el caso de Suecia entre 1750 -cuando el primer liberalismo cuestionó los viejos derechos- y el 2000, cuando la naturaleza supuestamente "absoluta" de la propiedad liberal fue cuestionada por una nueva conceptualización acerca de la naturaleza social de ciertos recursos naturales. También se refiere y compara los casos de Noruega y Dinamarca. Durante el siglo XVIII y gran parte del XIX, se trató de establecer derechos de propiedad absolutos e individuales sobre la tierra por parte del poder, para la práctica de una economía predominantemente agrícola. Desde finales del siglo XIX y en parte del siglo XX, se produce la expansión de los intereses industriales, que exigieron, en consecuencia, la renegociación política de nuevas reglas. A partir de entonces, una sociedad postindustrial produce un nuevo abanico de valores, tanto económicos como morales, sobre la apropiación colectiva de los recursos y la defensa del medio ambiente -que atañe especialmente al disfrute de los bosques- con las tensiones subsiguientes acerca de las apropiaciones competitivas. El autor muestra que los derechos de propiedad no se desarrollaron linealmente, sino de acuerdo con los cambios en el uso de la tierra, los conflictos de intereses y el equilibrio de poder. A medida que aparecen nuevos usos del suelo, surge la cuestión de la compatibilidad de diferentes tipos de derechos de uso organizados de varias maneras.

El capítulo de Andrea M. Locatelli y Paolo Tedeschi se centra en la contribución que las reformas institucionales, dirigidas por el estado en los derechos de propiedad en Lombardía, obraron desde la segunda mitad del siglo XVIII para cambiar la agricultura y acelerar el desarrollo económico, he hicieron de aquella una de las regiones más dinámicas y productivas de la Europa contemporánea. Como se advierte, se adopta una perspectiva que concuerda en gran medida con los principios de la nueva economía institucional. Una sucesión de reformas a los derechos de propiedad de la tierra que comenzaron en la Lombardía occidental del siglo XVIII como provincia del imperio austríaco, proseguidas bajo el gobierno napoleónico a principios del siglo XIX, y más tarde nuevamente bajo el dominio austríaco, fueron generalizadas a las otras áreas de la provincia lombarda. Tales reformas hicieron a los derechos de propiedad más definidos (catastro) y más ejecutables, y se complementaron con políticas de impuestos a la tierra de tal manera que crearon fuertes incentivos para el crecimiento económico. Se trata de una región que combinaba una economía agraria capaz de adaptarse a los cambios del mercado, con el desarrollo de un sistema urbano avanzado y 
un sector manufacturero potente. Los autores muestran que la adopción de estos cambios en la propiedad tuvo consecuencias duraderas, pero que a su vez dependió de un proceso de varios siglos y de dinámicas, recursos y actitudes sociales específicas del contexto lombardo. Sin embargo, no debe pensarse que estuvo exenta de aspectos negativos, tales como la proletarización del campesinado y la pauperización de algunos sectores de este, el endurecimiento de las condiciones de la aparcería, la venta de comunes que no mejoraron la productividad en las áreas montañosas, además de que la apropiación privada de la tierra causó un daño ambiental significativo.

Julio Djenderedjian y Daniel Santilli se concentran en el partido de Pergamino (provincia de Buenos Aires), una zona de antiguo asentamiento colonial que tuvo un importante crecimiento económico durante el siglo XIX, como toda la región pampeana que se vinculó al capitalismo internacional. Enmarcados en los estudios de los derechos de propiedad y de distribución de la riqueza, intentan dilucidar las claves de ese desempeño económico exitoso, aunque no compartido por todos (en el doble sentido histórico e historiográfico). Sobre la base de inventarios post mortem y datos censales, entre otras fuentes, argumentan que la distribución de la riqueza dependió de la consolidación de los derechos de propiedad y las inversiones necesarias para aplicar mejoras tecnológicas. Según los autores, los derechos consuetudinarios de ocupación de la tierra aplicados desde época colonial cedieron ante los derechos de propiedad apoyados desde el estado, consolidando una élite terrateniente en la primera mitad del siglo XIX. En ese período fue creciendo significativamente el precio de la tierra por sobre el de los otros bienes que componían el capital de una estancia (especialmente los ganados y las mejoras). Cuando, a partir de mediados del siglo, primero la producción lanera y luego la agrícola demandaron crecientes aumentos de capital en tecnología especialmente el alambrado-, este se transformó en un elemento de consolidación de los derechos de propiedad. Finalmente, refuerzan sus argumentos en una muy lograda comparación con el caso de las colonias de la provincia de Santa Fe, donde la menor posibilidad de criar lanares y una estructura de la tierra menos desigual, volcada tempranamente a la agricultura, determinó un resultado diferente en la distribución de la riqueza.

El capítulo realizado por Benedita Camara y Rui Santos centra su estudio en el espacio colonial portugués de la isla de Madeira y en los cambios en el régimen de las tenencias durante el siglo XIX, analizando específicamente la evolución de los contratos coloniales consuetudinarios y su forma de arrendamiento a largo plazo. Estas fórmulas tradicionales y señoriales "colisionaban" con los lineamientos del proyecto liberal del siglo XIX, tendientes a perfeccionar y universalizar los derechos de propiedad, como señalan los autores:

la materialización de este proyecto planteó el problema de encontrar un equilibrio entre la universalidad de la ley y la especificidad de la costumbre, bajo el principio general de la libertad contractual, y los desafíos cotidianos a la manera en que las nuevas formas institucionales se apropiaron y reasignaron en práctica social concreta.

La persistencia de estos contratos llamados de colonia -de antigua raigambre- practicados para el mejoramiento de las tierras de vides para la exportación, y defendidos por parte de los terratenientes y campesinos -"nuestro ornitorrinco metafórico"-, ha tendido a ser visto tradicionalmente como una "mezcla antinatural"de formas contractuales y de propiedad dispares cristalizadas por el tiempo, crítica negativa devenida de una vertiente liberal que chocaba doctrinalmente con el conjunto de prácticas imperantes en la isla.

La contribución de Samuel Garrido parte de analizar los derechos comunes de utilización del agua en las áreas de tierras de cultivo de regadío en los territorios del este de España, y los problemas de acción colectiva que el sistema plantea. El autor afirma:

los problemas de provisión surgen del hecho de que el suministro de bienes comunes (como, por ejemplo, limpieza de canales de riego) implica costos para los proveedores, sin embargo, los bienes resultantes están disponibles para todos, independientemente de la contribución individual de cada uno. 
Tomando en su análisis los trabajos teóricos de Elinor Ostrom en (1990) Governing the Commons sobre la administración colectiva de los bienes comunes, el autor plantea que los costos de supervisión del sistema tienden a minimizarse cuando los usuarios del sistema común, en lugar de una autoridad externa, realizan un control colectivo y ajustan sus necesidades individuales mediante deliberación colectiva. Para ello analiza y compara, a lo largo del capítulo, diferentes casos de instituciones creadas como comunidades de usuario.

El estudio que presentan Iñaki Iriarte-Goñi y José-Miguel Lana tiene la particularidad de emplear una rica documentación generada a propósito de la reforma agraria proyectada en la Segunda República Española durante la primera mitad de la década de 1930, y que no se llevó a cabo. Como bien dicen los autores, el interés de estos expedientes sobre la situación de los bienes comunes no solamente reside en que permiten estudiar los objetivos de la reforma que se proyectaba, sino que también, bien mirados tal como ellos lo hacen, posibilitan el análisis tanto de los resultados de las políticas de tierras anteriores como las esperanzas de cambio que tenían las comunidades agrarias españolas que respondieron a los requerimientos y "arrojan nueva luz sobre los cambios a largo plazo en los derechos de propiedad, lo que permite una mejor comprensión de su naturaleza social". La perspectiva regional les permite esbozar dos hipótesis relacionadas con el impacto de los procesos de privatización de los comunes en la etapa anterior y la presión sobre los recursos. Los resultados demuestran parcialmente que las regiones con más reclamaciones habían tenido procesos más profundos de privatización, y que "el hambre de tierras" también impulsó estos reclamos.

El último trabajo de investigación nos introduce en los problemas de la distribución de la tierra y las tensiones por la legalidad de uno y otro sistema en el este de Alemania, desde la separación en 1945 hasta la actualidad. Joyce E. Bromley y Axel Wolz realizan un didáctico racconto de las políticas sobre redistribución de tierras llevadas adelante por los gobiernos de la República Democrática Alemana entre 1945 y 1960 cuando se declara finalizada la colectivización, destacando las medidas llevadas adelante y el impacto que tuvieron, tanto en desplazamiento de familias en el propio territorio y hacia el oeste alemán, como en resultados económicos, teniendo siempre en cuenta los diferentes grupos de productores, desde los más pequeños a los más encumbrados. Luego, con la reunificación del país, prestan especial atención a los condicionamientos de política internacional que tuvieron las leyes agrarias, y destacan las mejores posibilidades que tuvieron los productores más pequeños para recuperar sus propiedades en diferentes sistemas de privatización, los cuales tuvieron, además, diferentes períodos de arrendamientos y posterior gradualismo en las ventas (para no distorsionar demasiado el mercado), como así también subsidios. Cierra el capítulo un estudio pormenorizado de ochenta casos de medianos y grandes propietarios desplazados en la etapa de la colectivización que luego de 1990 decidieron regresar, y cuyos intereses no habían sido tenidos en cuenta por los gobiernos de la unificación. La apelación a la memoria a través de entrevistas en profundidad les permite analizar, a ras del suelo, las múltiples aristas entre los sentimientos y las acciones de la sociedad agraria que recibió a los que volvían.

Finalmente, el trabajo de Rosa Congost, Jorge Gelman y Rui Santos, titulado Property rights in land Institutions, social appropriations, and socio-economic outcomes, viene a significar un balance teórico general del libro. Excelentemente logrado, por la calidad de los autores involucrados, los mismos parten de dos suposiciones básicas que el investigador de los problemas relacionados a los derechos de propiedad debe asumir como propias:

La primera es que el peso de los procesos, mediando entre una innovación institucional dada que afecta los derechos de propiedad, por un lado, y sus resultados económicos y sociales en diferentes sociedades, por el otro, es el resultado de las asignaciones sociales concretas de reglas y normas institucionales. Es decir, de cómo, por quién y con qué fines se utilizan realmente para legitimar el poder inherente a las relaciones de propiedad o la resistencia a ese poder. El segunda es que las apropiaciones sociales resultan de procesos históricos que involucran a múltiples agentes, y están demasiado arraigados en los contextos sociales como para ser reducidos a una descripción de los intereses y las acciones del estado y de las organizaciones de élite, por importantes que éstas sean. 
Ambas determinaciones condicionan una mirada más amplia del problema, componiendo el mismo dentro de un nivel multiescalar necesario para analizar las relaciones entre el espacio normativo propiamente dicho y las prácticas sociales con sus agentes histórico-socialmente constituidos. Este posicionamiento del investigador frente a un objeto complejo permite componer un verdadero Historical analysis versus tautological reasoning, que necesariamente tiene su punto genético en la propia historicidad de los fenómenos de propiedad a lo largo del tiempo y de las distintas sociedades. Sin duda un "reto" de envergadura para la investigación histórica, al que esta edificante lectura nos convoca. 